\title{
Functional Analyses of the Pto Resistance Gene Family in Tomato and the Identification of a Minor Resistance Determinant in a Susceptible Haplotype
}

\author{
Jeff H. Chang, ${ }^{1,2}$ Yin-Shan Tai, ${ }^{1}$ Adriana J. Bernal, ${ }^{1}$ Daniel T. Lavelle, ${ }^{1}$ Brian J. Staskawicz, ${ }^{1,3}$ and \\ Richard W. Michelmore ${ }^{1,4}$ \\ ${ }^{1}$ NSF Center for Engineering Plants for Resistance Against Pathogens (CEPRAP), University of California, Davis, \\ One Shields Avenue, Davis, 95616 U.S.A.; ${ }^{2}$ Current Address: Department of Biology, 108 Coker Hall CB \#3280, \\ Chapel Hill, NC 27599, U.S.A.; ${ }^{3}$ Department of Plant and Microbial Biology, University of California, Berkeley, 94720 , \\ U.S.A.; ${ }^{4}$ Department of Vegetable Crops, University of California, Davis, 95616 U.S.A.
}

Submitted 24 April 2001. Accepted 4 December 2001.

Pto is a member of a multigene family and encodes a serine/threonine kinase that mediates gene-for-gene resistance to strains of Pseudomonas syringae pv. tomato expressing avrPto. The inferred amino acid sequence of the Pto homologs from both resistant (LpimPth2 to LpimPth4,) and susceptible (LescFen, LescPth2 to LescPth5) haplotypes suggested that most could encode functional serine/threonine kinases. In addition, the activation segments of the homologs are similar in sequence to that of Pto, and some have residues previously identified as required for binding of AvrPto by Pto in the yeast two-hybrid system. The Pto homologs were therefore characterized for transcription, for the ability of their products to interact with AvrPto in the yeast two-hybrid system, for their autophosphorylation activity, and for their potential to elicit cell death in the presence of and absence of a ligand, as well as their dependence on Prf. LpimPth5, LpimPth4, and LescPth4 were not transcribed at levels detectable by reverse transcription-polymerase chain reaction. The interaction with AvrPto was unique to Pto in the yeast two-hybrid system. LescPth2 autophosphorylated in vitro as a fusion protein. LpimPth2, LpimPth3, LpimPth4, LescPth3, and LescPth4 did not autophosphorylate in vitro. Transient expression of wild-type Fen and wild-type LpimPth3, as well as LescFen, LescPth3, and LescPth5 with perturbations in their P+1 loop caused cell death in Nicotiana benthamiana. LpimPth3 and LescPth3 with amino acid substitutions in the $P+1$ loop also elicited cell death in tomato; this was dependent on the presence of wild-type $\operatorname{Prf}$. Consequently, some homologs could potentially encode functional resistance proteins. LescPth5 induced cell death specifically in response to expression of AvrPto in tobacco in a Prfdependent manner; this is consistent with a homolog from a 'susceptible' haplotype encoding a minor recognition determinant.

Resistance of plants to pathogenic organisms is often initiated by the recognition of avirulence proteins of the pathogen

Corresponding author: R. W. Michelmore; Telephone: +1-916-752-1729; Fax. +1-916-752-9659; E-mail: rwmichelmore@ucdavis.edu

Nucleotide sequence data reported are available in the GenBank database under the accession numbers AF220602 and AF220603. by corresponding resistance proteins of the plant (Baker et al. 1997; Flor 1956; Scofield et al. 1996; Tang et al. 1996). A defense response is elicited in these incompatible interactions, suppressing disease symptoms and pathogen growth (Dangl et al. 1996; Glazebrook 1999). A common characteristic of resistance is the hypersensitive response (HR) that involves rapid plant cell death at the point of infection (Goodman and Novacky 1994). In contrast, the lack of specific recognition permits a compatible interaction in which pathogen growth occurs and the plant succumbs to disease.

Classical and molecular studies have shown that resistance genes are often clustered in the genome (Michelmore and Meyers 1998). However, there are few data on the function of resistance gene homologs within a cluster. In addition to the gene conferring the primary resistance, a few homologs have been shown to confer partial resistance. $\mathrm{Xa21}$ is the member of a gene family that is necessary and sufficient to confer resistance to strains of Xanthomonas oryzae pv. oryzae expressing the cognate avirulence gene (Song et al. 1995, 1997). However, transgenic rice plants expressing another family member, $X a 21 D$, exhibited partial resistance to $X$. oryzae pv. oryzae in a race-specific manner (Wang et al. 1998). Similarly, $C f-9$ is clustered with homologous genes in tomato and confers resistance to Cladosporum fulvum strains expressing avr9 (Jones et al. 1994; Parniske et al. 1997). Two homologs of $C f-9$ conferred partial resistance in the adult tomato to isolates of $C$. fulvum with and without avr9 (Parniske et al. 1997). Further analysis identified a naturally occurring chimeric gene $\mathrm{Hcr} 9 \mathrm{DC}$ that also encoded recognition of Avr9 (Van der Hoorn et al. 2001). In both rice and tomato, it was necessary to study the homologs independently of the primary resistance gene to reveal the abilities of the homologs to confer resistance.

Kinases are integral components of most signal transduction pathways. The catalytic core of kinases consists of approximately 300 residues encompassing twelve uninterrupted subdomains folded into a bilobal structure (Hanks and Hunter 1995). Twelve of the approximately 300 residues are essentially invariant among kinases. These twelve invariant residues and a commonality in structure have provided a basis for predicting functions and structural relationships of kinases. Many kinases are regulated through phosphorylation events in their activation segments at a sequence referred to as the P+1 loop (Johnson et al. 1996). Perturbing the activation segment, for example, by substituting the phosphorylated residue in the $\mathrm{P}+1$ loop for a negatively charged amino acid such as aspartic acid or glu- 
tamic acid can mimic activation of a kinase (Johnson et al. 1996; Rathjen et al. 1999).

Pto encodes a serine/threonine kinase and confers resistance to strains of Pseudomonas syringae pv. tomato carrying the avirulence gene, avrPto (Loh and Martin, 1995; Martin et al. 1993). Pto requires Prf, a nucleotide binding site-leucine rich repeat (NBS-LRR) encoding gene, to confer resistance (Salmeron et al. 1996). Pto is expressed in Lycopersicon esculentum cv. Rio Grande 76R, but the gene is absent in the two susceptible cultivars, 'Rio Grande 76S' and 'VFNT Cherry'. In contrast, Prf is present in all three cultivars. Pto interacts with AvrPto in the yeast two-hybrid system (Scofield et al. 1996; Tang et al. 1996) and functions in transgenic Nicotiana benthamiana to provide resistance to $P$. syringae pv. tabaci expressing avrPto (Rommens et al. 1995b). Aspartic acid substitutions at several positions in the $\mathrm{P}+1$ loop of Pto resulted in constitutive gain-of-function mutants of Pto (Rathjen et al. 1999).

We had previously sequenced the Pto locus from 'Rio Grande 76R' and 'VFNT Cherry' and partially sequenced the locus of 'Rio Grande 76S' (accession numbers AF220602 and AF220603; D. Lavelle and R. Michelmore unpublished data). In 'Rio Grande 76R', the Pto locus contains Prf and a family of six homologous open reading frames (ORFs) that were introgressed from L. pimpinellifolium, including Pto and Fen (Fig. 1). Consistent with the naming convention proposed by Price and associates (1996), paralogs (homologs generated by a gene duplication event) of Pto in the resistant haplotype have been designated LpimPth2 to LpimPth5 (for L. pimpinellifolium Pto homologs). LpimPth5 has two mutations causing frameshifts in its ORF and is, therefore, considered to be a pseudogene (D. Lavelle and R. Michelmore unpublished data). The Pto homologs of 'VFNT Cherry' and 'Rio Grande 76S' are similar and colinear with those of the resistant haplotype, except for deletions due to unequal crossing events (Fig. 1) (D. Lavelle and R. Michelmore unpublished data). These homologs are designated LescFen and LescPth2 to LescPth5 (for L. esculentum Pto homologs). Homologs with the same number are orthologs (homologs separated by a speciation event and occupying a syntenic position), as identified by sequence similarity and the same position in the haplotype. The homolog LescPth 5 was previously designated as the pto allele (Jia et al. 1997). However, neither susceptible Pto haplotype has an exact ortholog of Pto, due to an unequal crossover event resulting in a deletion of over half of the Pto orthologs in 'Rio Grande 76S' (D. Lavelle and R. Michelmore unpublished data). The haplotypes of 'VFNT Cherry' and 'Rio Grande 76S' are similar, except that homolog LescPth3 is absent in 'Rio Grande 76S' due to a second deletion event.

The susceptible haplotype may encode a minor recognition determinant of AvrPto. P. syringae pv. tomato expressing avrPto causes enhanced necrosis on plants of both 'Rio Grande 76S' and prf-3 (Chang et al. 2000). However, symptoms are delayed and less severe in plants of 'Rio Grande 76S' than prf3. These are near-isogenic lines that differ only at the Pto lo-

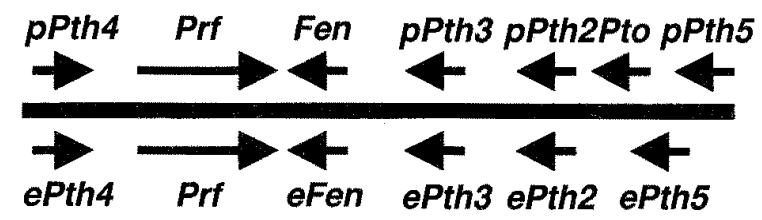

Fig. 1. Diagram of the Pto locus from Lycopersicon esculentum cvs. Rio Grande 76R and VFNT Cherry. The arrows above and below the bar represent the arrangement of the genes in 'Rio Grande 76R' and 'VFNT Cherry', respectively. Their direction indicates the direction of transcription. $\mathrm{p}=\mathrm{Lpim}, \mathrm{e}=$ Lesc. The locus spans approximately $65 \mathrm{~kb}$. Not drawn to scale. cus; prf-3 is a mutant line of 'Rio Grande 76R' that lacks a functional Prf gene (Salmeron et al. 1996) and 'Rio Grande 76S' has a functional Prf gene but not Pto. In addition, plants of 'Rio Grande 76S' respond to Agrobacterium-mediated transient expression of avrPto with a nonconfluent HR, whereas no macroscopic phenotype was observed in plants of prf-3 (Chang et al. 2000). Therefore, one of the Pto homologs from 'Rio Grande $76 \mathrm{~S}$ ' or Prf might encode a minor recognition determinant of AvrPto.

To investigate the possibility of functional resistance activities at the Pto locus, the Pto homologs were characterized for activities similar to that of Pto. The homologs were analyzed for expression, interaction with AvrPto in the yeast two-hybrid system as well as in planta, and autophosphorylation activity. Substitutions were also introduced into the $\mathrm{P}+1$ loop of each of the Pto homologs to create potential gain-of-function mutants that were then tested for elicitation of cell death in the absence of a ligand. Those that elicited cell death were also characterized for their dependence on Prf in tomato and tobacco.

\section{RESULTS}

Transcription of the Pto homologs in planta.

Polymerase chain reaction (PCR) was used to amplify reverse-transcribed mRNA from tomato cultivars Rio Grande 76R, Rio Grande 76S, and 'VFNT Cherry', in order to identify transcribed homologs of Pto. The mRNA samples were first assessed for DNA contamination by amplifying a portion of $\operatorname{Prf}$ with primers that span the intron located between the regions encoding the putative NBS and LRR motifs (Salmeron et al. 1996). Reverse transcription-polymerase chain reaction (RT-PCR) products of Prf from each of the mRNA samples were identical in size to the amplified product of a cDNA clone of Prf and approximately $100 \mathrm{bp}$ smaller than the amplified product from genomic DNA of 'Rio Grande 76R' (Fig. 2). Therefore, the mRNA isolated from each cultivar of tomato was free from detectable amounts of DNA.

Primers that spanned the ORFs of the Pto homologs (Table 1) were used in RT-PCR of mRNA from each of the three genotypes. First-strand cDNA samples from each genotype were amplified with primer pairs for Pto, the Pth3 orthologs, and the Pth5 orthologs. Samples from 'Rio Grande 76R' and 'Rio Grande 76S' were also amplified with three primer pairs unique to the Fen orthologs, Pth2 orthologs, and the Pth4 orthologs. An amplification product was obtained for each pair of primers from all mRNA samples tested, except for those de-

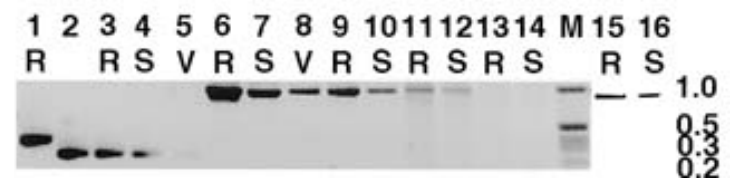

Fig. 2. Reverse transcription-polymerase chain reaction (RT-PCR) of transcripts corresponding to the Pto homologs from tomato cultivars, Rio Grande 76R (R), Rio Grande 76S (S), and VFNT Cherry (V). This is a negative image of a $1.0 \%, 1 \times$ Tris-Acetate EDTA, ethidium bromidestained agarose gel. Lanes 1 to 5 show products amplified with primers that span an approximately 300-bp genomic fragment of Prf; lanes 1 and 2 show products amplified from a genomic fragment and a corresponding cDNA clone of Prf, respectively; and lanes 3 to 5 show PCR products of reverse transcribed mRNA. A faint band of approximately $200 \mathrm{bp}$ is visible in lane 5. Lanes 6 to 14 depict products from reverse transcribed mRNA. Products in lanes 6 to 8 were amplified with primers to Pto, the Pth3 orthologs, and LescPth5. Products in lanes 9 and 10, 11 and 12, and 13 and 14 were amplified with primers to the Fen orthologs, Pth2 orthologs, and Pth4 orthologs, respectively. Lanes 15 and 16 show the products of the Pth4 orthologs amplified from genomic DNA. One-kb ladder is designated with a "M" and sizes in $\mathrm{kb}$ are shown to the right. 
signed to amplify LpimPth4 and LescPth4 (Fig. 2). All amplification products were cloned and from 15 to 20 clones were sequenced from each product. Products corresponding to Pto, Fen, LpimPth2, and LpimPth3 were identified from mRNA of 'Rio Grande 76R'. However, products for LpimPth5 were not detected using this particular primer pair. Transcripts of LescFen, LescPth2, and LescPth5 were detected from mRNA of 'Rio Grande 76S'; LescPth3 was transcribed in 'VFNT Cherry'. The lack of amplification of LpimPth4 and LescPth4 was not due to primer sequence or PCR conditions; LpimPth4 and LescPth4 were successfully amplified from genomic DNA samples using the same primer pair and PCR conditions. The same mRNA samples were used successfully as templates for the other homologs (Fig. 2). Consequently, the absence of amplification of the Pth4 orthologs by RT-PCR was due to a lack of detectable transcription rather than a lack of amplification. Therefore, transcription of all Pto homologs was detected except for LpimPth5, LpimPth4, and LescPth4.

\section{Yeast two-hybrid analysis of interactions with the Pto homologs.}

Sequence similarities to subdomain VIII of Pto suggested that several homologs could potentially interact with AvrPto (Fig. 3). LpimPth3, LescPth3, and LescPth5 have the highest overall levels of amino acid identity with Pto. They have the threonine in subdomain VIII that is suggested to be a critical AvrPto-binding determinant of Pto (Scofield et al. 1996; Frederick et al. 1998). LpimPth4 and LescPth4 have the lowest overall levels of amino acid identity with Pto. However, the translation products of both have the amino acids KxTLxxxD in subdomain VIII that were present in Pto but not present in Fen and that were required in chimeric proteins between Fen and Pto for recognition of AvrPto (Scofield et al. 1996, Tang et al. 1996). LpimPth2 and LescPth2 are the most divergent from Pto at this particular sequence.

We used the Gal4 yeast two-hybrid system to test whether any of the Pto homologs could interact with AvrPto. Pto homologs from 'Rio Grande 76R' were fused to both the Gal4 DNA-binding domain and the Gal4 DNA-activating domain, whereas Pto homologs from 'Rio Grande 76S' and 'VFNT Cherry' were only fused to the Gal4 DNA-binding domain. Regardless of the vector used, $\beta$-galactosidase was not activated in yeast cells cotransformed with AvrPto and any Pto homolog except Pto (Fig. 4A). Gal4 DNA-binding domain fusions with LescFen activated $\beta$-galactosidase in the absence of AvrPto, suggesting a nonspecific interaction with the Gal4 DNA-activating domain. Expression of each protein in yeast was confirmed by Western analysis (Chang 1999). Therefore, detectable specific interaction with AvrPto in the yeast two-hybrid system was unique to Pto.
To determine whether any of the Pto homologs from the resistant haplotype could recognize Pto-signaling components, each homolog was individually paired with Pto or Ptil in the yeast two-hybrid system. Again, no interactions were detected (Fig. 4B). Finally, no interactions were detected when Pto homologs of the resistant haplotype were paired with themselves or together with other Pto homologs.

\section{In vitro autophosphorylation assays.}

Analysis of the amino acid sequence of the Pto homologs suggested they may encode functional kinases (Fig. 3). Each homolog, with the exception of LpimPth3 and LescPth3, has the twelve invariant residues characteristic of functional kinases (Hanks and Hunter 1995). LpimPth3 and LescPth3 have an alanine substituted for the first invariant glycine (position 48 in Pto). Pto, Fen, LescFen, and LescPth5 had each been previously shown to autophosphorylate in vitro (Jia et al. 1997; Loh and Martin 1995; Rommens et al. 1995a).

The Pto homologs were fused to the maltose binding protein (MBP), partially purified, and subjected to in vitro autophosphorylation assays. Proteins were boiled and then separated in denaturing gel and reducing conditions that would disrupt all noncovalent associations. Coomassie-stained gels of all partially purified proteins showed that each was expressed and purified to detectable levels (Chang 1999). Only Pto, Fen, and LescPth2 autophosphorylated in vitro (Fig. 5). Neither LescFen nor LescPth5 were tested as they had previously been demonstrated to autophosphorylate (Jia et al. 1997). Proteins from the other homologs tested did not autophosphorylate. Therefore, in addition to Pto, Fen, LescFen, and LescPth5, LescPth2 autophosphorylated in vitro. However, LpimPth2, LpimPth3, LpimPth4, LescPth3, and LescPth4 did not autophosphorylate in vitro as MBP fusions.

\section{Elicitation of cell death in planta by Agrobacterium- mediated transient expression of Pto homologs.}

Elicitation of cell death by the Pto homologs was examined by Agrobacterium-mediated transient expression in N. benthamiana. The Pto homologs were fused to the CaMV35S promoter and the Tobacco mosaic virus RNA $\Omega$ leader sequence. DNA constructs were transformed into A. tumefaciens strain A281, and strains were individually infiltrated into leaves of $N$. benthamiana (Fig. 6). Cell death was observed approximately 5 days postinoculation (dpi) in leaves infiltrated with A. tumefaciens carrying either wild-type LpimPth3 or Fen. Other wildtype Pto homologs did not elicit a visible phenotype when transiently expressed after infiltration with $A$. tumefaciens. T-DNA transfer and gene transcription was confirmed by assaying for GUS activity and by RT-PCR of the transgene in infiltrated leaves, respectively (Chang 1999). Therefore, of the wild-type

Table 1. Summary of oligonucleotide primers used in the analysis of the Pto gene family

\begin{tabular}{|c|c|c|c|}
\hline Gene & Flanking primers ${ }^{a}$ & Cognate to 204 substitution $^{b}$ & Cognate to 207 substitution $^{b}$ \\
\hline LescFen & $\begin{array}{l}\text { 5'GGTCACCATGGGAAGCAAGTATTC } \\
\text { 5'GTGAGAGGAGATATAGGCTAC }\end{array}$ & $\begin{array}{l}\text { 5'GGGTCTAGATCATTCAGGATCATC } \\
\text { 5'CAGGGGCAATGTCGCCTATATTTC }\end{array}$ & $\begin{array}{l}\text { 5'GTAGCCTATATCTCCTCTCAC } \\
\text { 5'GGAAATATAGGCGACATTGCCCCTG }\end{array}$ \\
\hline $\begin{array}{l}\text { LpimPth2 and } \\
\text { LescPth2 }\end{array}$ & $\begin{array}{l}\text { 5'CACGGATCCCCATGGGAACCAACTATTCC } \\
\text { 5'GGGTCTAGAGTCATTCAGGATTATCTG }\end{array}$ & $\begin{array}{l}\text { 5'GTAGCCTATATCTGGTTGCACC } \\
\text { 5'GGTGCAAGGAGATATAGGCTAC }\end{array}$ & $\begin{array}{l}\text { 5'GGTCAATGTCGCCTATACTTG } \\
\text { 5'GAAGTATAGGCGACATTGACC }\end{array}$ \\
\hline $\begin{array}{l}\text { LpimPth3 and } \\
\text { LescPth5 }\end{array}$ & $\begin{array}{l}\text { 5'GGTCACCATGGGAAGCAAGTATTC } \\
\text { 5'GGCTCTAGATTAAATAACAGACTCTTGGAG }\end{array}$ & $\begin{array}{l}\text { 5'GTAGCCGAAATCTCCTTTCACGTC } \\
\text { 5'GACGTGAAAGGAGATTTCGGCTAC }\end{array}$ & $\begin{array}{l}\text { 5'CAGGGTCAATGTCGCCGAAAGTTC } \\
\text { 5'GAACTTTCGGCGACATTGACCCTG }\end{array}$ \\
\hline LescPth3 & $\begin{array}{l}\text { 5'GGTCACCATGGGAAGCAAGTATTC } \\
\text { 5'GGCTCTAGATTAAATAACAGACTCTTGGAG }\end{array}$ & $\begin{array}{l}\text { 5'GTAGCCGAGATCTCCTTGCACTAC } \\
\text { 5'GTAGTGCAAGGAGATCTCGGCTAC }\end{array}$ & $\begin{array}{l}\text { 5'CAGGGTCAAGGTCGCCGAGAGTTC } \\
\text { 5'GAACTCTCGGCGACCTTGACCCTG }\end{array}$ \\
\hline $\begin{array}{l}\text { LpimPth4 and } \\
\text { LescPth4 }\end{array}$ & $\begin{array}{l}\text { 5'AGAAGCAAGGATTCCAAGGAAAC } \\
\text { 5'GCCTCTAGACTACAGCACATCACCCACAG }\end{array}$ & $\begin{array}{l}\text { 5'GTACCCCAAATCTCCGTTTCACG } \\
\text { 5'CGTGAAAGGAGATTTGGGGTAC }\end{array}$ & $\begin{array}{l}\text { 5'GGTCAAGGTCCCCCAAAGTT C } \\
\text { 5'GAACTTTGGGGGACCTTGACC }\end{array}$ \\
\hline
\end{tabular}

a Sequences of the primers that anneal immediately outside the ORFs.

${ }^{\mathrm{b}}$ Sequences of the primers used to introduce substitutions at positions cognate to 204 and 207 of Pto for each gene. 
subdomain I

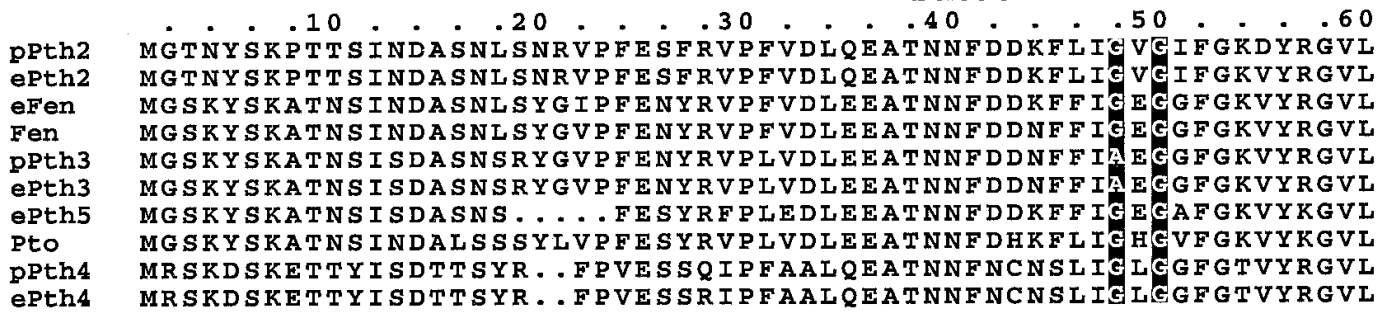

subdomain II subdomain III subdomain IV sub-

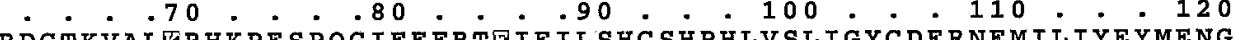

PPth2 RDGTKVALKRRKPESPQGIEEFRTIIEILSHCSHPHLVSLIGYCDERNEMILIYDYMENG eFen RDGTKVALKKHKRESSOGIEEFETEIEILSFCSHPHLVSLIGFCDERNEMILIYDYMENG Fen RDGTKVALKKHKPESSQGIEEFETEIEILSFCSHPHLVSLIGFCDERNEMILIYDYMENG

PPth3 RDGTKVALKRHNCDQQSIEEFRTEIEILSRRSHPHLVSLIGYCDGRNEMIIIYDYMENG ePth3 RDGTKVALKRHNCDQQSIEEFRTEIDILSRRSHPHLVSLIGYCDERNEMILIYDYMENG ePth5 RDGTKVALKRONRDSROGIEEFGTEIGILSRRSHPHLVSLIGYCDERNEMVIIYDYMENG Pto RDGAKVALKRRTPESQGIEEFETEIETLSFCRHPHLVSLIGFCDERNEMILIYKYMENG pPth4 CDGTKVALKRCKLESSQGIEEFQTEIEMLSHFRHPYLVSLIGYCDENNVTIIIFKYMENG ePth4 CDGTKVALKRCKLESSQGIEEFQTEIEMLSHFRHPYLVSLIGYCDENNVTIIIFKYMENG

\section{domain $\mathrm{V}$ subdomain $\mathrm{VIa}$ subdomain $\mathrm{VIb}$}

. . 130 . . . 140 . . . 150 . . . 160 . . . 170 . . 180 pPth2 NLSKRLYGSDLCLPTMSWEQRLEICIGAARGLHYLHNSAVIHCDVKSTIILIDENFVAKI EPTh2 NLSKRLYGSDLCLPTMSWEQRLEICIGAARGLHYLHNSAVIHRDVKSTNILLDENFVAKI eFen NIKSHLYGDLPTMSMWEQRLEICIGAARGLHLHTNGVIHRDVKCTNILLDENFVPKI Fen NLKSHLYGSDLP. . SMSWEQRLEICIGAARGLHYLHKNAVIHRDVKCTNILIDENFVPKI pPth3 NLKSHLYGSDLP.. SMSWEORLEICIGAARGLHYLHTNGVMHRDVKS SNILIDENFVPKI ePth3 NLKSHLYGSDLP. . SMSWEQRLEICIGAARVLHYLHTNGVMHRDVKSSNILIDENFVPKI ePth5 NLKSHLTGSDLP. . SMSWEQRLEICIGAARGLHYLHTNGVMHRDVKSSNIIIDENFVPKI Pto NLKRHLYGSDLPTMSMSWEQRLEICIGAARGLHYLHTRAIIHRDVKSINILIDENFVPKI pPth4 SLSSHLYGSYLP. . TMTWEQRLEICIGAARGLYYLHKNAVIHRDVKSANILIDENFVAKT ePth4 SISSHLYGSYLI . TMTWEQRLEICIGAARGLHYLHKNAVIHRDVKSANILIDENFVAKT

subdomain VII subdomain VIII subdomain IX

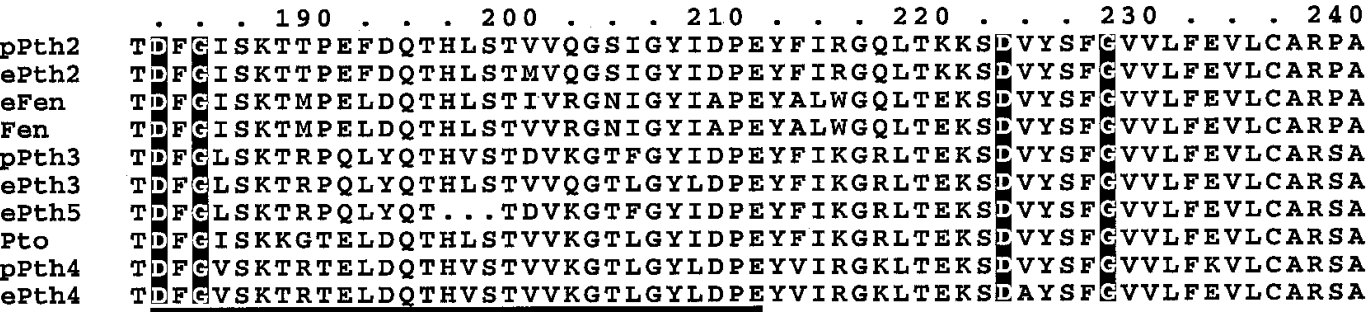

\section{$\stackrel{\star \star ⿱ 十}{*}^{\star}+$ subdomain $x^{\star}$}

sub-

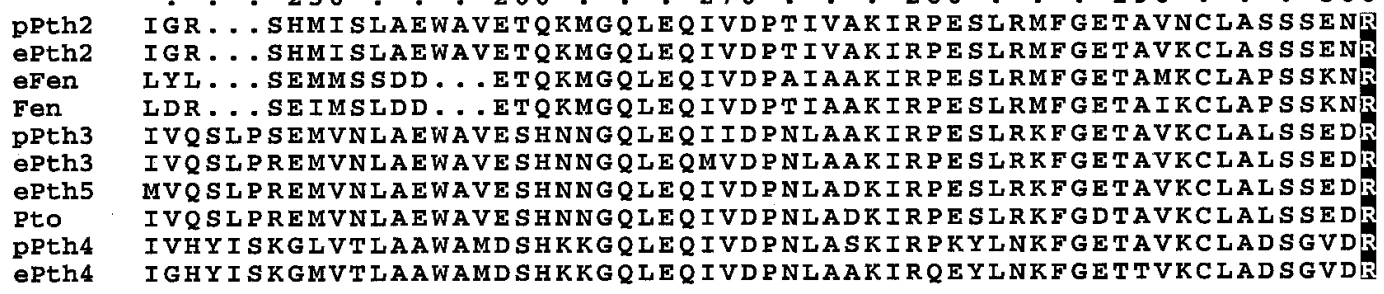

domain XI

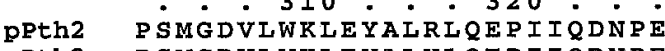

ePth2 PSMGDVLWKLEYALHLQEPIIQDNPE

EFEN PSMGDVIWKLEYALCLQEPTIQDDPE

Fen PSMGDVLWKLEYALCLQEPTIQDDPE

PPTh3 PSMGDVLWKLEYALRLQESVI.....

PETh3 PSMGDVLWKLEYALRLQESVI. . .

EPTh5 PSMGDVLWKLEYALRLOESVI. . .

Pto PSMGDVLWKLEYALRLQESVI . . . .

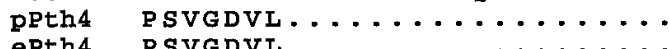

Fig. 3. Amino acid alignment of the Pto homologs. Amino acids were aligned using ClustalX (Thompson 1997) and Macboxshade 2.15E (M. D. Baron). Gaps are represented by periods. The 12 invariant resides of a kinase are depicted by black columns. The putative activation segments are underlined with a black bar. The putative $\mathrm{P}+1$ loop of each homolog begins at the position corresponding to $\mathrm{G}^{203}$ in Pto, and extends to the end of the activation segment. Variable residues between Pto and Fen found in the region previously shown to be required to confer AvrPto binding by chimeric proteins are depicted with an asterisk and positions 204 and 207 of Pto are marked with a "+" under the black bar. Putative subdomains of the Pto homologs are based on inferences from other kinases. $\mathrm{p}=$ Lpim, $\mathrm{e}=$ Lesc. 
genes, overexpression of only LpimPth3 and Fen elicited cell death in N. benthamiana.

To determine if Pto homologs could be modified to elicit cell death, amino acid substitutions were made in each of the Pto homologs that were analogous to substitutions that created ligand-independent, constitutive gain-of-function mutants of Pto (Rathjen et al. 1999). The amino acid sequences in the P+1 loop of the Pto homologs show conservation of threonines and identity of tyrosines at positions corresponding to 204 and 207, respectively, of Pto (Fig. 3). Aspartic acid substitutions at these positions in Pto resulted in mutants that constitutively elicited cell death following Agrobacterium-mediated transient expression assays in N. benthamiana (Rathjen et al. 1999).

Infiltration of A. tumefaciens carrying LpimPth3, LescFen, LescPth3, and LescPth5 with substitutions corresponding to T204D or Y207D of Pto elicited cell death in leaves of $N$. benthamiana (Fig. 6). The leaves collapsed in a manner similar to leaves infiltrated with $A$. tumefaciens carrying either wild-type LpimPth3 or Pto ${ }_{\text {Y207D }}$ (Rathjen et al. 1999), except the cell death responses caused by LescPth3 and LescPth5 with substitutions cognate to position 204 in Pto were weaker and delayed

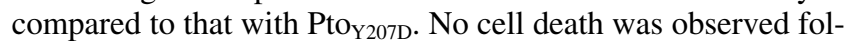
lowing infiltrations of LpimPth2, LescPth2, LpimPth4, or LescPth4 with substitutions in either position; transcription in these cases was confirmed by RT-PCR using primers specific to the transgene and mRNA isolated from leaves infiltrated with A. tumefaciens (Chang 1999).

Elicitation of cell death by Fen, Pto+AvrPto, and constitutive gain-of-function mutants of Pto are dependent on Prf. Therefore, we assayed the Pto homologs that do elicit cell death for their dependence on Prf in both $N$. benthamiana and tomato. Plants of $N$. benthamiana were inoculated with Potato virus $X$ (PVX) expressing a $3^{\prime}$ fragment of Prf derived from $N$. benthamiana to induce silencing (Baulcombe 1999) of the Prf gene. Three weeks later, these plants were infiltrated with A. tumefaciens carrying either the test constructs or $\mathrm{PtO}_{\mathrm{L} 205 \mathrm{D}}$ (as the control). None of the constructs elicited HR, demonstrating that the silencing of Prf was effective and that in all cases the HR elicited in wild-type plants was dependent of Prf (Fig. 7). In addition, these Pto homologs were introduced into A. tumefaciens strain $\mathrm{C} 58 \mathrm{C} 1$ and infiltrated into tomato genotypes, 'Rio Grande 76R' and prf-3. LpimPth3 and LescPth3, carrying an aspartic acid substitution at position 207, caused cell death in 'Rio Grande 76R', but no cell death was observed in prf-3. All other Pto homologs and those carrying perturbations in the $\mathrm{P}+1$ loop that caused cell death in $N$. benthamiana did not exhibit phenotypes in tomato. (This was not surprising as transient assays in tomato are less reliable than those in tobacco and require lower bacterial densities than those in $N$. benthamiana to avoid a nonspecific HR induced by Agrobacterium alone.) These data indicate that the gain-of-function variants of the Pto homologs induce HR through one or more of the same signaling pathways as wild-type Pto.

\section{Recognition of AvrPto by a Pto homolog in transgenic $N$. benthamiana.}

In order to determine whether any of the Pto homologs could recognize AvrPto in planta, we tested them using $N$. benthamiana carrying a dexamethasone (DEX)-inducible avrPto transgene. Twenty-five constructs encoding each of the Pto homologs or their potentially gain-of-function variants were expressed in the transgenic N. benthamiana using Agrobacterium-mediated transient assays. Plants were treated with 30 $\mu \mathrm{M}$ DEX $36 \mathrm{~h}$ postinoculation to induce expression of AvrPto. No cell death was observed with 13 of the 14 constructs that had previously failed to elicit cell death in the absence of AvrPto; therefore, there was no evidence that LpimPth2,
LpimPth4, LescFen, LescPth2, LescPth3, and LescPth4 could recognize AvrPto. However, LescPth5 elicited a clear HR specifically in response to the induced expression of AvrPto within $24 \mathrm{~h}$ of DEX treatment, and therefore, had a similar phenotype to Pto infiltrated into these plants (Fig. 8). Therefore, LescPth5 that is present in the supposedly susceptible haplotype of tomato is capable of recognizing AvrPto in tobacco. To test whether this cell death was Prf dependent, transgenics with DEX-inducible AvrPto expression were inoculated with PVX expressing a $3^{\prime}$ fragment of Prf from tobacco to silence the Prf gene. No cell death was observed in these plants following infiltration 3 weeks later with Agrobacterium carrying LescPth 5 or $P t o_{\mathrm{L} 205 \mathrm{D}}$, indicating that the HR induced by LescPth5 in response to the expression of AvrPto is Prf dependent (Fig. 8).

\section{DISCUSSION}

We characterized the Pto homologs from both resistant and susceptible haplotypes of tomato to determine whether they have activities similar to that of Pto (Table 2). Based on sequence data, several Pto homologs could potentially encode functional resistance proteins. However, a specific recognition activity was only demonstrated for one homolog. Several lines of evidence had indicated that 'Rio Grande 76S', which is isogenic with the resistant 'Rio Grande 76R', has a minor recognition of the AvrPto component at the Pto locus but that this is not sufficient to suppress disease completely. Although 'Rio Grande $76 \mathrm{~S}^{\prime}$ is susceptible to Pst expressing avrPto, it shows less extensive symptoms relative to those observed in the mutant prf-3 that lacks Prf activity (Chang et al. 2000). Similar differences were observed when 'Rio Grande 76S' and prf3 plants were challenged with PVX::avrPto (Tobias et al. 1999). 'Rio Grande $76 \mathrm{~S}$ ' also shows a weak and nonconfluent HR in response to Agrobacterium-mediated transient expression of AvrPto (Chang et al. 2000).

Our current data is consistent with LescPth5 encoding the minor recognition determinant in cv. Rio Grande 76S. When LescPth5 was transiently expressed in $N$. benthamiana, it elicited a strong HR specifically in response to the expression of AvrPto. This HR was comparable in timing and intensity to the HR caused by the interaction of Pto with AvrPto. Furthermore, LescPth5 autophosphorylated in vitro and with amino acid substitutions in the $\mathrm{P}+1$ loop elicited ligand-independent cell death in $N$. benthamiana. The cell death elicited both by LescPth5+AvrPto and by the activated LescPth5 were Prf dependent. Our failure to detect interactions between LescPth5 and AvrPto in yeast when using the GAL 4 system and by others using the LexA system (Jia et al. 1997) may be a consequence of a lack of sensitivity of the yeast two-hybrid system to detect weak interactions. The differences in the extent of the HR observed in transient assays of transgenic N. benthamiana and tomato challenged with Pst expressing AvrPto may reflect differences among the experimental systems in providing different levels of both LescPth5 and AvrPto. Alternatively, it may reflect differences among proteins regulating the HR response; these differences may also explain why transient expression of several Pto homologs resulted in cell death in N. benthamiana but not tomato.

LescPth5 is a chimera resulting from an unequal crossover event between progenitor sequences of Pto and LpimPth5. The crossover event occurred within the region encoding the kinase activation domain between amino acids 189 and 206, resulting in a gene that is similar to the $5^{\prime}$ two-thirds of LpimPth5 and the $3^{\prime}$ third of Pto (Fig. 3). LescPth5 has a 3-amino acid deletion just $\mathrm{N}$-terminal to the $\mathrm{P}+1$ loop compared with Pto and other homologs. LescPth5 and Pto have the same residues at three out of four positions, equivalent to $\mathrm{K}^{202}, \mathrm{~T}^{204}$, and $\mathrm{D}^{209}$ in 
Pto, that were shown to be important in recognition of AvrPto by using exchanges between Pto and Fen (Scofield et al. 1996; Tang et al. 1996; Frederick et al. 1998) and by alanine substitution analysis (Rathjen et al. 1999). LescPth5 has a phenylalanine at the position, equivalent to $\mathrm{L}^{205}$ in Pto, at which aspartic acid substitutions result in constitutive gain-of-function variants in Pto and several homologs, including LescPth5. These, or some of the other 49 amino acid differences between LescPth5 and Pto elsewhere in the protein, have apparently altered the ability to recognize AvrPto in the yeast two-hybrid system but have not completely abolished the recognition or the downstream signaling, as indicated by the in planta data.

The other homologs of Pto could also potentially encode functional resistance genes, although we have no indication of the ligand that they detect. Transcription of all genes was detected except for LpimPth4, LescPth4, and the pseudogene LpimPth5. Fen exhibited the majority of the tested activities of Pto; in addition, Fen elicited cell death in the absence of activating substitutions in N. benthamiana. LescFen exhibited similar activities to Fen except that the wild-type LescFen sequence did not elicit cell death in $N$. benthamiana. LpimPth3 and LescPth3 did not autophosphorylate but did elicit cell death as the wild-type sequence or with activating substitutions, respectively. Conversely, LescPth2 did autophosphorylate but was not activated by the amino acid substitutions used in this study. LpimPth2, LpimPth4, and LescPth4 had none of the tested activities, even though they had complete ORFs and had all of the 12 residues invariant in protein kinases. The Pto homologs that did not elicit cell death can only be considered nonfunctional to the extent that activation segment substitutions and the conditions used in this study failed to elicit cell death.
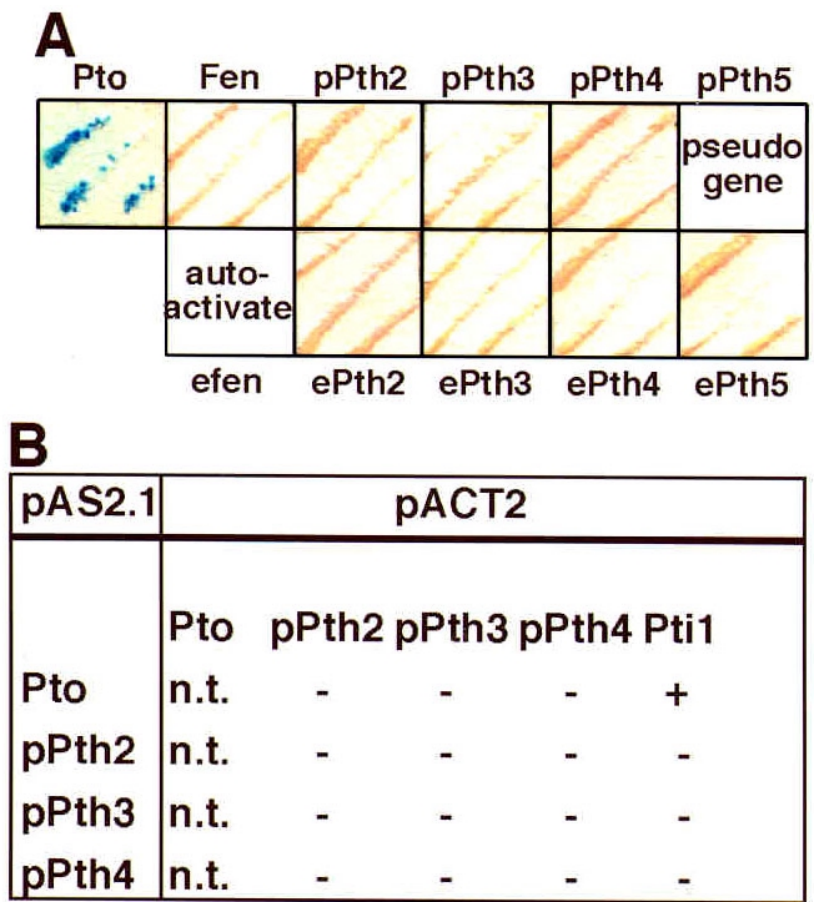

Fig. 4. Gal4 yeast two-hybrid assays of the Pto homologs. Yeast cells were incubated in X-Gal for no longer than $24 \mathrm{~h}$. Blue cells are indicative of a positive interaction. A, Top row, assays for interactions between AvrPto and Pto homologs of the resistant haplotype; bottom row, assays for interactions between AvrPto and Pto homologs of susceptible haplotypes. LpimPth5 was not tested because it is a pseudogene and LescFen interacted with an empty Gal4 DNA-activating domain (autoactivation). B, Assays for interactions between the Pto homologs of the resistance haplotype and Ptil. $+=$ an interaction as confirmed by $\beta$-galactosidase activity; $-=$ no detectable interaction; n.t. = could not be tested because Pto autoactivated when expressed in pACT2; $\mathrm{p}=\mathrm{Lpim}$; and e = Lesc.
The Pto homologs may recognize as yet unidentified ligands from $P$. syringae or from other pathogens. Transgenic tomato plants with either of two homologs of $C f-9$ conferred partial resistance to $C$. fulvum independent of avr9 (Parniske et al. 1997). It is difficult to identify the natural ligands for putative orphan receptors such as the Pto homologs. It is similarly difficult, in the absence of genetic information that maps additional resistance to the Pto locus, to identify pathogens against which these homologs might confer resistance. Stable transgenics are of limited value in determining function of Pto homologs; no genetic stocks exist in which the Pto locus has been deleted, and therefore, disease assays would be confounded by the presence of endogenous Pto homologs. In addition, stable transgenics expressing CaMV35S::LpimPth3, CaMV35S::Fen, and gain-of-function mutants have reduced viability (Chang 1999).

Autophosphorylation in vitro was not always correlated with the elicitation of cell death in planta. LescPth2 autophosphorylated but did not elicit cell death. Conversely, wild-type LpimPth3 elicited cell death even though it had no detectable in vitro autophosphorylation activity; similarly, LescPth3 did not autophosphorylate in vitro but did elicit cell death with substitutions in its $\mathrm{P}+1$ loop. Therefore, the role of autophosphorylation activity in downstream signaling leading to cell death is unclear. Signaling independent of detectable autophosphorylation in vitro by a kinaselike molecule has been previously shown in the mammalian interleukin-1 receptor (IL-1R) pathway (Kopp and Medzhitov 1999). This pathway elicits innate immunity (Qureshi et al. 1999); one component, IRAK, contains a functional kinase domain with high homology to Pto (Cao et al. 1996). IRAK-2, a homolog of IRAK, associates with the IL-1R complex, and activates NF- $\kappa B$ when ecotopically expressed (Muzio et al. 1997); however, IRAK-2 lacks residues critical to kinase function and does not autophosphorylate in vitro (Wesche et al. 1999). In addition, IRAK-M, another IRAK homolog, can partially restore the IL-1 response in the absence of IRAK; it, too, does not autophosphorylate in vitro and lacks residues critical for kinase function (Wesche et al. 1999). Therefore, LpimPth3 and LescPth3 may belong to this class of molecules that do not require autophosphorylation activity to signal. Furthermore, our results indicate that autophosphorylation is not a prerequisite for eliciting the HR. This is contrary to the conclusions of Sessa and associates (2000). However, it is consistent with our previous observations that autophosphorylation activity was dispensable for interaction

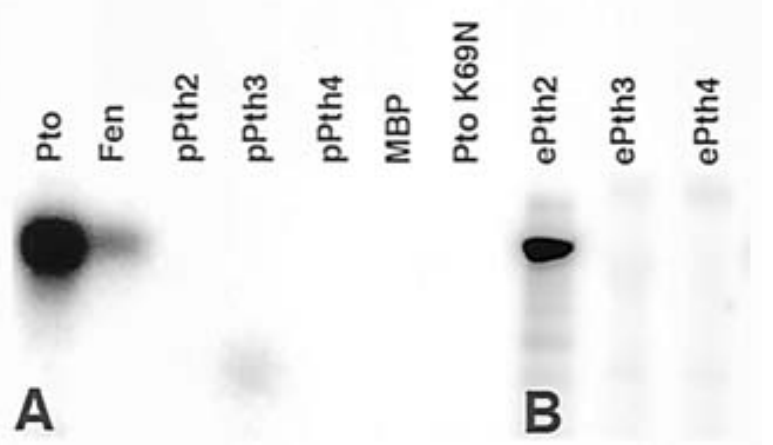

Fig. 5. In vitro autophosphorylation assays of the Pto homologs. Pto homologs were cloned as fusions to maltose binding protein and partially purified proteins were incubated with $\gamma^{32} \mathrm{P}$-ATP. Protein products were resolved by sodium dodecyl sulfate-polyacrylamide gel electrophoresis on a $12 \%$ acrylamide gel and assayed for autophosphorylation activity. Radiolabeled proteins were detected using a phosphoimager. Data are representative of at least three separate kinase assays; this figure is compiled from two images of kinase assays of $\mathbf{A}$, resistant and $\mathbf{B}$, susceptible Pto homologs. $\mathrm{p}=$ Lpim, e = Lesc. 
with avrPto in yeast and that Pto $_{Y 207 D}$ lacked autophosphorylation activity (Rathjen et al. 1999).

The lack of detectable autophosphorylation activity in vitro for LpimPth2, LpimPth3, and LescPth3 might be explained by divergence from consensus sequences for kinases. Subdomain I has the motif $\underline{G} \underline{G x} \operatorname{GxV}$ that forms a flexible cap to hold the nontransferable phosphates of ATP (Hanks and Hunter 1995). Although not invariant, this valine is highly conserved among kinases and may contribute to a hydrophobic pocket that encloses the adenine ring of ATP (Hanks and Hunter 1995). LpimPth2 has an aspartic acid rather than valine at this position, and this negatively charged residue may repel the negative charges of ATP. The first of the residues in the glycine triad of subdomain I is usually invariant in kinases. LpimPth3 and LescPth3 have an alanine instead of a glycine at this position. Alanine has a slightly larger side group than glycine, possibly adding rigidity to this motif and preventing proper orientation of ATP; substitutions from glycine to alanine at this position in mouse cAMP-dependent protein kinase decreased catalytic activity (Hemmer et al. 1997). However, we cannot exclude the possibility that the Pto homologs that did not show autophosphorylation activity are functional kinases but do not autophosphorylate in vitro as MBP fusion proteins.

The functional analyses of the proteins encoded by genes at the Pto locus support our inferences regarding the evolution of this cluster based on sequence analysis (Michelmore and Meyers 1998; D. Lavelle and R. Michelmore unpublished data). Orthologs are more similar at the sequence level than paralogs. Orthologs between resistance and susceptible haplotypes also exhibited parallel transcription and tended to have similar abilities to elicit cell death and kinase activity (Table 2). LpimPth2 and LescPth2 are the only orthologs that did not have similar autophosphorylation activities; however, critical kinase residues differed between these two proteins. Homologs LpimPth4 and LescPth4 are the most divergent members at the sequence level compared with the other Pto homologs. They also seem to be the least functional. Neither was transcribed at detectable levels; also, LpimPth4 and LescPth4 were unable to elicit cell death with substitutions in their putative activation segments and did not autophosphorylate in vitro, despite having all 12 invariant residues of serine/threonine kinases.

Recently, Pto homologs have been isolated from a cDNA library of L. hirsutum by crosshybridization to Pto (Riely and Martin 2001). Several of the results from the characterization of L. hirsutum homologs parallel ours. The orthologs LhirPto, LhirFen, LhirPth2, and LhirPth5 were identified on the basis of sequence similarity to the homologs that we had characterized previously. However, orthologs LhirPth4 and LhirPth3 were not identified. This is consistent with little or no tran- scription of LhirPth4; similarly, we did not detect transcription of LpimPth4 or LescPth4. We were able to detect transcription of LescPth3 from cv. VFNT Cherry, but not in cv. Rio Grande 76S. However, it is possible that both LhirPth4 and LhirPth3 are transcribed but have insufficient sequence similarity to have been isolated by crosshybridization with Pto. Consistent with our observations, of all the L. hirsutum homologs, only LhirPto interacted with AvrPto in the yeast two-hybrid system. Finally, like LescPth2, LhirPth2 autophosphorylated in vitro. Together, these data indicate that not only did recognition of AvrPto by Pto arise before the diversification of $L$. hirsutum from L pimpinellifolium, but that multiple members of the Pto gene family were present before diversification and that the spectrum of activities encoded at this locus has remained relatively static. This may indicate that there are selective advantages for the different activities of genes at this locus.

\section{MATERIALS AND METHODS}

\section{Isolation of RNA.}

Tissue (2 $\mathrm{g}$ ) was ground in liquid nitrogen using a mortar and pestle and was vortexed in $10 \mathrm{ml}$ solution $\mathrm{D}$ (4 M guanid-

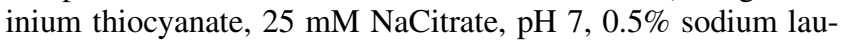
rylsarcosyl, $30 \mu \mathrm{l} \beta$-mercaptoethanol) that had been treated with $0.1 \%$ diethylpyrocarbonate (DEPC), $200 \mathrm{mM} \mathrm{NaOAc}, \mathrm{pH}$ 4.5, $10 \mathrm{ml}$ phenol, and $2 \mathrm{ml}$ chloroform. Total RNA was precipitated in $2 \mathrm{M}$ LiAc overnight at $4^{\circ} \mathrm{C}$, resuspended in $0.1 \%$ DEPC-treated water, digested with 4 units of DNase I for 30 min, and treated with a 1:1 phenol/chloroform mixture. mRNA was isolated using the PolyATtract mRNA Isolation System (Promega, Madison, WI, U.S.A.). First-strand cDNA was synthesized from 100 ng of mRNA using the ProStar First-Strand kit (Stratagene, La Jolla, CA, U.S.A.). PCR was performed with gene-specific primers flanking the complete ORFs (Table 1) for 30 cycles at $92^{\circ} \mathrm{C}$ for $1 \mathrm{~min}, 57^{\circ} \mathrm{C}$ for $1 \mathrm{~min}$, and $72^{\circ} \mathrm{C}$ for $1 \mathrm{~min}$. Products were cloned into the vector, pCR Blunt (Invitrogen, Carlsbad, CA, U.S.A.) and sequenced.

Cloning of the Pto homologs and yeast two-hybrid analysis. LescFen was amplified from cv. Rio Grande 76S using Pfu polymerase (Stratagene) (Table 1) and cloned into the vector, pCR Blunt (Invitrogen). LescFen was reamplified with primers that incorporated $\mathrm{NcoI}$ and XhoI restriction enzyme sites, digested with the appropriate restriction enzymes, and cloned into pAS2.1 (Clontech, Palo Alto, CA, U.S.A.) that had been digested with NcoI and SalI.

LpimPth2 was identified from a cDNA library prepared from mRNA of 'Rio Grande 76R' (J. Salmeron, unpublished data). The complete ORF was amplified with Pfu polymerase

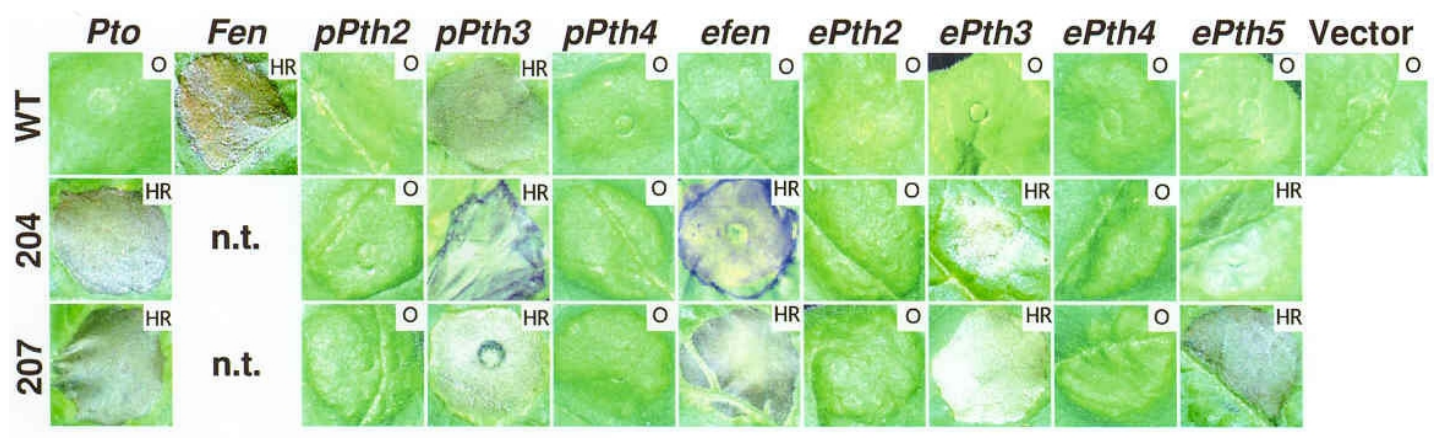

Fig. 6. Agrobacterium-mediated transient expression of Pto homologs in Nicotiana benthamiana. The top row shows Agrobacterium-mediated transient expression of wild-type Pto homologs (WT). The second row shows Agrobacterium-mediated transient expression of Pto homologs carrying aspartic acid substitutions at positions equivalent to 204 of Pto, and the third row shows Pto homologs carrying substitutions at positions equivalent to 207 of Pto. HR $=$ hypersensitive response $(\mathrm{HR}) ; \mathrm{O}=$ lack of $\mathrm{HR} ;$ n.t. $=$ not tested; $p=$ Lpim; and $e=$ Lesc. 
(Stratagene) (Table 1). An adenine was added to the blunt ends by adding 1 unit of Taq polymerase and incubating the reaction at $72^{\circ} \mathrm{C}$ for $10 \mathrm{~min}$. Products were cloned into vector pCR II (Invitrogen). LpimPth2 was then digested with $\mathrm{NcoI}$ and EcoRI and cloned into the corresponding sites of pAS2.1. LescPth2 was amplified from 'Rio Grande 76S' (Table 1) using Pfu polymerase and cloned into pCR Blunt (Invitrogen). LescPth2 was then digested with $\mathrm{NcoI}$ and $\mathrm{XhoI}$ and cloned into pAS2.1 that had been digested with NcoI and SalI.

The complete ORFs of LpimPth3, LescPth3, and LescPth5 were amplified from 'Rio Grande 76R' and 'Rio Grande 76S' using Pfu polymerase (Table 1). LpimPth3 and LescPth3 were cloned into pCR2.1 (Invitrogen), after the addition of an adenine. LpimPth3 was then digested with $N c o$ I and EcoRI and cloned into the corresponding sites of pAS2.1. LescPth5 was

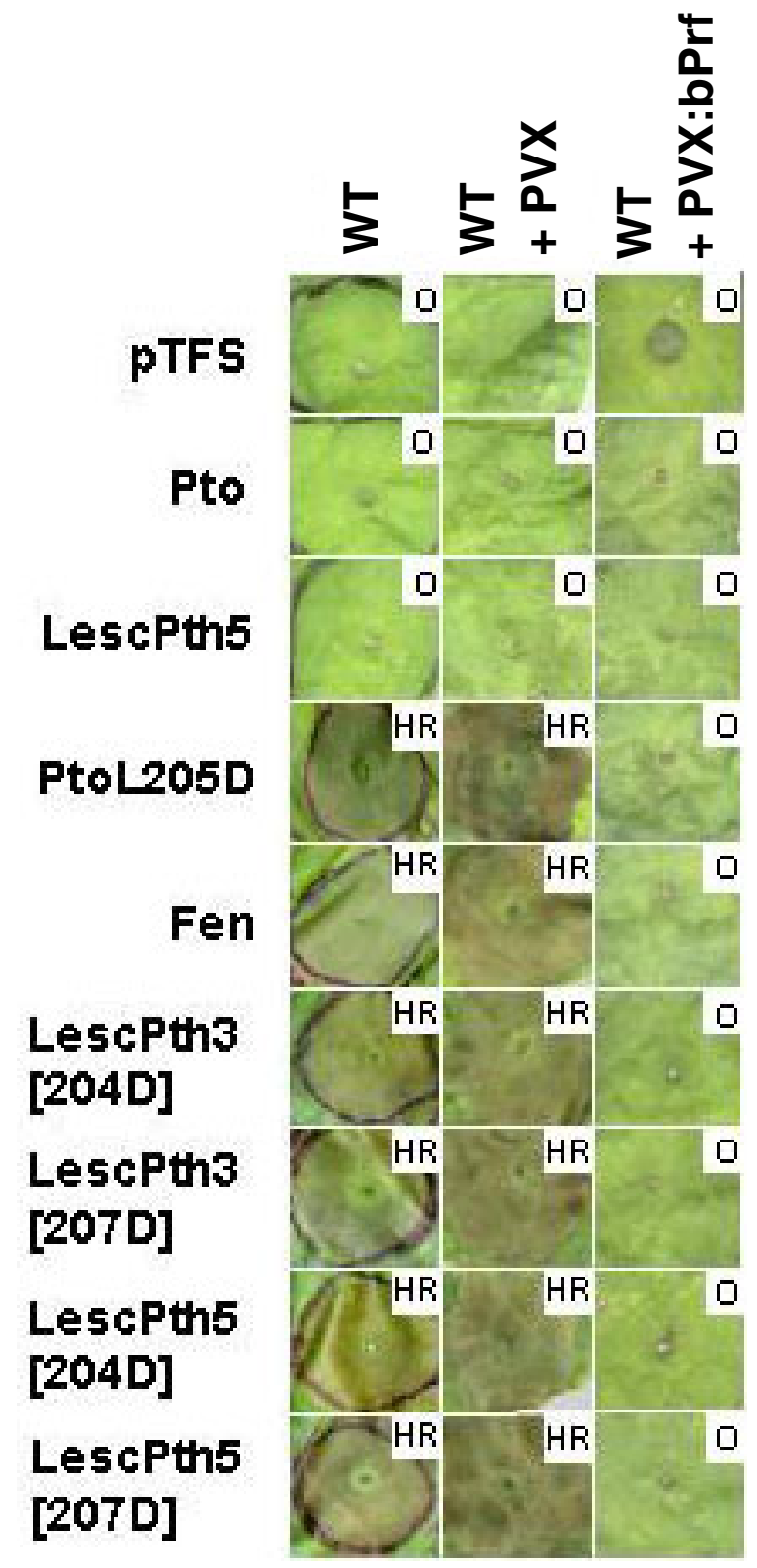

Fig. 7. Prf dependence of hypersensitive response (HR) induced by Pto homologs. The first column shows the reactions of wild type Nicotiana benthamiana (WT) without inoculation with Potato virus $X$ (PVX). The second column shows the reaction of plants following inoculation with wild-type PVX. The third column shows the reaction of plants inoculated with PVX expressing a 600-bp fragment of the $3^{\prime}$ region of Prf from $N$. benthamiana . $\mathrm{HR}=$ hypersensitive response; $\mathrm{O}=$ lack of $\mathrm{HR}$; n.t. $=$ not tested; $p=$ Lpim; and $e=$ Lesc. cloned in pAS2.1 that had been digested with SmaI and treated with calf intestinal phosphatase. LescPth3 was digested with $X b a$ I, filled-in with Klenow according to the manufacturer's instructions (New England Biolabs, Beverly, MA, U.S.A.) and digested with $N c o$ I. The insert was cloned into pAS2.1 that had been digested with $N c o$ I and SmaI.

The complete ORFs of LpimPth4 and LescPth4 were amplified from 'Rio Grande 76R' and 'Rio Grande 76S', respectively, using primers 5'GGAGCTCATGAGAAGCAAGGATTCC and 5'TCTAGACTACAGCACATCACCCACAGATGG and $P f u$ polymerase. LpimPth4 was cloned into pCR2.1 (Invitrogen) after the addition of an adenine. LpimPth4 was then digested with EcoRI and ligated to pAS2.1 that had been digested with EcoRI and treated with calf intestinal phosphatase. The PCR product of LescPth4 was cloned directly into pAS2.1 that had been digested with $S m a I$ and treated with calf intestinal phosphatase.

Orientation of each ORF relative to the GAL4 DNA binding domain was verified by PCR and restriction digest. Both strands of all PCR products were sequenced to verify no mutations had been introduced. Yeast two-hybrid analysis was conducted using the MATCHMAKER GAL4 system following the protocols of the manufacturer (Clontech). Pto homologs were transformed into Y190 yeast cells. Cotransformed yeast cells were selected by growth on selective media and replicated on filters (Whatman No. 1) prior to assaying for activation of $\beta$ galactosidase using 5-bromo-4-chloro-3-indolyl $\beta$-D-galactoside (X-gal).

\section{E. coli expression and in vitro autophosphorylation assay.}

The ORFs of the Pto homologs were cloned into pMAL-c2 (New England Biolabs) as EcoRI-XbaI fragments derived from each cloned PCR product.

Each was transformed into DH5 $\alpha$ and was expressed according to the manufacturer's instructions (New England Biolabs). Cultures were grown overnight at $37^{\circ} \mathrm{C}$ with shaking and were diluted 1:100 in $200 \mathrm{ml}$ of Luria-Bertani (LB) media. Protein expression was induced with $1.0 \mathrm{mM}$ isopropyl- $\beta$-D-thiogalactoside when cells had reached an optical density at $600 \mathrm{~nm}$ $\left(\mathrm{OD}_{600}\right)$ of approximately 0.4 . Cells were grown for an additional $2 \mathrm{~h}$ at $37^{\circ} \mathrm{C}$ with shaking. Cells were pelleted, washed once in column buffer $(20 \mathrm{mM}$ Tris- $\mathrm{HCl}, \mathrm{pH} 7.4,200 \mathrm{mM}$ $\mathrm{NaCl}, 1.0 \mathrm{mM}$ EDTA, $1.0 \mathrm{mM}$ phenylmethylsulfonyl fluoride [PMSF], $5.0 \mu \mathrm{g}$ of leupeptin per $\mathrm{ml}$, and $1.0 \mathrm{mM}$ dithiothreitol [DTT]), and pelleted again. Cells were resuspended in $10 \mathrm{ml}$ of column buffer and lysed by sonication. The recombinant protein was partially purified on amylose resin by batch purification.

Proteins were subjected to in vitro autophosphorylation assays (Goring and Rothstein 1992; Rathjen et al. 1999). Resin was washed twice in $200 \times$ vol of column buffer and once with kinase buffer (30 mM Tris-HCl, pH 7.5, $20 \mathrm{mM}$ HEPES [N-2hydroxyethylpiperazine- $N^{\prime}$-2-ethanesulfonic acid], $\mathrm{pH} 7.1,10$ $\mathrm{mM} \mathrm{MgCl} 2,2.0 \mathrm{mM} \mathrm{MnCl} 2$ [Douville et al. 1992] with 1.0 $\mathrm{mM}$ PMSF and $1.0 \mathrm{mM}$ DTT). The resin and retained recombinant protein was resuspended in $50 \mu \mathrm{l}$ of kinase buffer containing $25 \mu \mathrm{Ci}$ of $\gamma^{32} \mathrm{P}$-ATP $(6000 \mathrm{Ci} / \mathrm{mmol})$ and incubated at room temperature for $30 \mathrm{~min}$. The resin was pelleted, washed with $200 \times$ vol of kinase buffer, and resuspended in $20 \mu \mathrm{l}$ of $2 \times$ sodium dodecyl sulfate (SDS)-loading dye. The samples were heated at $90^{\circ} \mathrm{C}$ for approximately $5 \mathrm{~min}$ and separated by SDSpolyacrylamide gel electrophoresis on a $12 \%$ acrylamide gel. The gel was dried overnight and visualized on a phosphoimager.

\section{Mutagenic PCR and generation of constructs for in planta transient expression.}

Recombinant PCR was performed using Pfu polymerase and gene specific primers (Scofield et al. 1996; Table 1). Products 
were cloned into pCR Blunt (Invitrogen). Mutations were confirmed by sequencing both strands. Wild-type and recombinant sequences, except for the Pth4 orthologs, were digested with NcoI and $X b a I$ and ligated to compatible sites in pSLJ4D4 between the CaMV35S:: $\Omega$ and ocs3' sequences (Jones et al. 1992). Clones were then digested with EcoRI and HindIII, and the entire expression cassette was ligated to compatible sites in the binary T-DNA vector, pTFS40 (British Sugar Corp., Norwich, U.K.).

The PCR products of the Pth4 orthologs were digested with XbaI. Vector pSLJ4D4 was digested with NcoI, filled-in with Klenow, and digested with XbaI. Digested PCR prod- ucts of the Pth4 orthologs were then cloned into the digested pSLJ4D4 vector. This created an in-frame fusion starting at the second codon of the Pth4 orthologs. Mutations were confirmed by sequencing both strands. The Ocs $3^{\prime}$ sequence of pSLJ4D4 was digested with XbaI and HindIII and ligated to compatible sites in pTFS40. Wild-type LpimPth4 and mutagenized clones in pSLJ4D4 were then digested with EcoRI and $X b a \mathrm{I}$ and ligated upstream of the Ocs $3^{\prime}$ sequence in pTFS40. Wild-type LescPth4 and mutagenized ORFs in pSLJ4D4 were then digested with $\mathrm{XbaI}$ and partially digested with EcoRI and ligated upstream of the Ocs $3^{\prime}$ sequence in pTFS40.

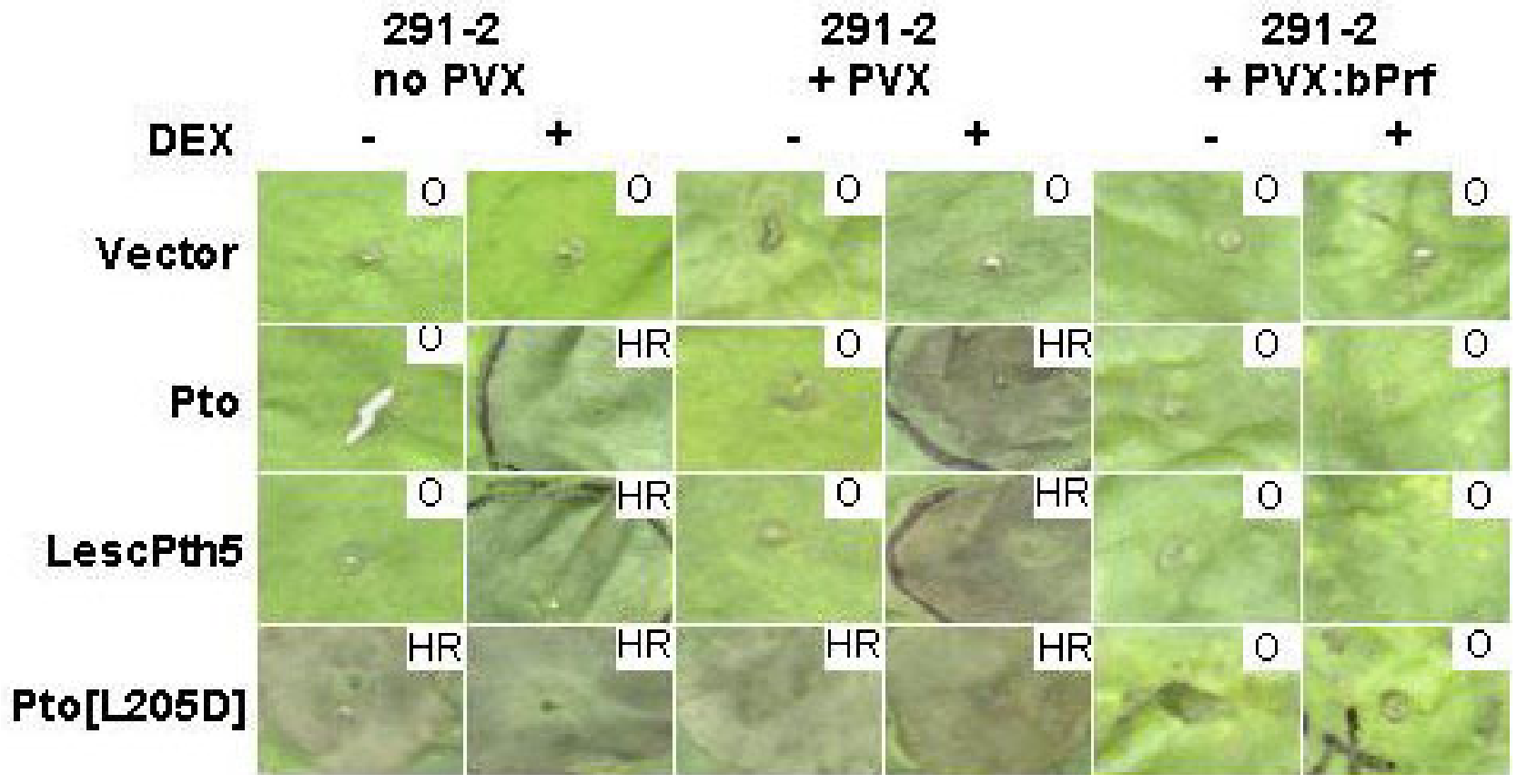

Fig. 8. Recognition of AvrPto by LescPth5 in Nicotiana benthamiana. Homozygous transgenic plants of N. benthamiaina line 291-2 with a dexamethasone (DEX)-inducible avrPto transgene were inoculated with either PVX, PVX carrying a 600-bp fragment of Prf from N. benthamiana, or left uninoculated. After 3 weeks, previously uninoculated leaves were infiltrated with Agrobacterium carrying the empty vector pTFS40 (negative control), Pto (positive control for the expression and specific recognition of AvrPto), Pto ${ }_{\mathrm{L} 205 \mathrm{D}}$ (positive control for virus-induced gene silencing of Prf), and LescPth5, as well as other homologs (not shown). Plants were either mock inoculated (-) or treated with $30 \mu \mathrm{M} \mathrm{DEX} \mathrm{(+)} 36 \mathrm{~h}$ after infiltration.

Table 2. Activities of the Pto homologs

\begin{tabular}{|c|c|c|c|c|c|c|c|}
\hline \multirow[b]{2}{*}{ Homolog } & \multirow[b]{2}{*}{ Transcription } & \multirow{2}{*}{$\begin{array}{l}\text { Interaction with } \\
\text { AvrPto in } \mathrm{Y}^{2} \mathrm{H}^{\mathrm{a}}\end{array}$} & \multirow[b]{2}{*}{ Autophosphorylation ${ }^{b}$} & \multirow{2}{*}{$\begin{array}{l}\text { AvrPto dependent } \\
\text { HR in planta }\end{array}$} & \multicolumn{3}{|c|}{ HR induction in planta ${ }^{d}$} \\
\hline & & & & & WT & $\Delta 204$ & $\Delta \mathbf{2 0 7}$ \\
\hline Pto & $++^{\mathrm{e}}$ & $+^{\mathrm{f}}$ & $+^{\mathrm{g}}$ & + & $-^{\mathrm{h}}$ & $++^{\mathrm{h}}$ & $+^{\mathrm{h}}$ \\
\hline Fen & $+^{\mathrm{e}}$ & $-{ }^{f}$ & $+^{g}$ & n.t. & + & n.t. & n.t. \\
\hline LpimPth2 & + & - & - & - & - & - & - \\
\hline LpimPth3 & + & - & - & n.t. & + & + & + \\
\hline LpimPth4 & - & - & - & - & - & - & - \\
\hline LpimPth5 & - & n.t. & n.t. & n.t. & n.t. & n.t. & n.t. \\
\hline Lescfen & $+{ }^{i}$ & - & $+^{\mathrm{i}}$ & - & - & + & + \\
\hline LescPth2 & + & - & + & - & - & - & - \\
\hline LescPth3 & + & - & - & - & - & + & + \\
\hline LescPth4 & - & - & - & - & - & - & - \\
\hline LescPth5 & $+^{\mathrm{i}}$ & - & $+^{\mathrm{i}}$ & + & - & + & + \\
\hline
\end{tabular}

${ }^{\mathrm{a}}+=$ interacted with AvrPto; $-=$ did not interact with AvrPto.

b $+=$ autophosphorylated in vitro; $-=$ did not autophosphorylate in vitro.

$\mathrm{c}_{+}=$elicited cell death in transgenic Nicotiana benthamiana after treatment with $30 \mu \mathrm{M}$ dexamethasone, $-=$ no cell death,

${ }^{\mathrm{d}}+=$ elicited cell death in $N$. benthamiana; $-=$ did not elicit cell death; n.t. = not tested, either a pseudogene or the wild type induced HR in the absence of AvrPto.

e Martin et al., 1993.

f Scofield et al. 1996; Tang et al. 1996.

g Loh and Martin 1995.

${ }^{\mathrm{h}}$ Rathjen et al. 1999.

i Jia et al. 1997. 
Generation of transgenic plants

with DEX-inducible expression of Avrpto.

The avrPto gene was amplified by PCR using Klentaq (Clontech) and Pfu (Stratagene) polymerases and oligonucelotide primers to introduce terminal XhoI and Spe sites and an N-terminal HA-tag to the translated protein (5'CTCGAGATGGGAAATATATGTGTCGGCGG and 5'ACTAGTTCAAGCGTAATCTGGAACATCGTATGGGTATTGCCAGTTACGGTA), cloned into pTOPO (Invitrogen), and then subcloned as an XhoI-Spe fragment into pTA7002 (Aoyama and Chua 1997). This binary vector carrying the AvrPto gene was transformed into the Agrobacterium strain LBA4404 by the freeze and thaw method. $N$. benthamiana plants were transformed as described by Horsch and associates (1985). Several independent transgenic lines were obtained. Southern and segregation analyses confirmed the presence of a single T-DNA insertion in line 291-2. This line was selfed to provide homozygous families for use in this study. The induction of AvrPto expression only upon application of $30 \mu \mathrm{M}$ DEX was confirmed by Western blots using AvrPto antibody, as well as by the lack of HR induction by Pto in the absence of DEX.

\section{Agrobacterium-mediated transient expression in planta.}

DNA constructs were transformed by the freeze and thaw method or electroporation into A. tumefaciens strains A281 or C58C1 for infiltration of $N$. benthamiana or tomato respectively. For transient expression assays, overnight cultures were diluted 1:10 in LB media, $200 \mu \mathrm{M}$ acetosyringone, and $20 \mu \mathrm{g}$ of kanamycin per $\mathrm{ml}$, plus $5 \mu \mathrm{g}$ of tetracycline per $\mathrm{ml}$ for strain $\mathrm{C} 58 \mathrm{C} 1$, and grown at $30^{\circ} \mathrm{C}$ overnight. Cultures were washed in infiltration media $\left(1 / 10 \times\right.$ Murashige-Skoog [MS] salts, ${ }^{1} / 10 \times \mathrm{B} 5$ vitamins, $20 \mathrm{mM}$ MES [morpholineethanesulfonic acid], 2\% [wt/vol] sucrose, 1\% [wt/vol] glucose, $200 \mu \mathrm{M}$ acetosyringone, $\mathrm{pH} 5.4$ ) and diluted to an $\mathrm{OD}_{600}$ of 1.0 or 0.3 for $N$. benthamiana or tomato, respectively. A. tumefaciens was pressure infiltrated, using a syringe, into leaves of approximately 6-week-old $N$. benthamiana plants or 4-weekold tomato plants. Plants were grown at $21^{\circ} \mathrm{C}$ for 4 to 5 days and then scored for the presence of cell death. For analysis of interactions with AvrPto in planta, AvrPto expression was induced in the transgenic $N$. benthamiana plants $36 \mathrm{~h}$ after infiltration with Agrobacterium by applying a $30 \mu \mathrm{M}$ DEX solution with a cotton swab to the upper surface of the leaves. The photographs in Figures 6,7 , and 8 were taken 5 $\mathrm{dpi}$; the results shown are representative of at least three separate infiltrations.

\section{Virus-induced gene silencing (VIGS) of Prf.}

In order to generate plants of $N$. benthamiana lacking expression of Prf, a 600-bp fragment of Prf was amplified from $N$. benthamiana by PCR, using primers designed from the $3^{\prime}$ part of the Prf ORF from tomato that introduced terminal ClaI sites (5'-CCATCGATGCCCTTCTGTGGCGCCCATC$3^{\prime}$ and $5^{\prime}$-CCATCGATGCTTGAGGAACTCAAGGTGGCTTAG-3'). This was cloned as a 600-bp fragment into Agrobacterium binary vector pGR106 which contains PVX downstream of a $35 \mathrm{~S}$ promoter (Baulcombe et al. 1995). Single leaves of 4-week-old plants were infiltrated with Agrobacterium strain C58C1 carrying the construct. Infected plants developed mottled symptoms characteristic of PVX infection throughout the plant. Three weeks after infection, transient assays were performed as above by infiltrating younger leaves than those originally inoculated with PVX. VIGS was confirmed in every experiment by infiltration with Agrobacterium strains carrying the constitutively HRinducing $\mathrm{Pto}_{\mathrm{L} 205 \mathrm{D}}$.

\section{ACKNOWLEDGMENTS}

We thank J. Rathjen, L. Rose, and B. Gabel for valuable discussions, P. Ronald for her critical reading of the manuscript, J. Gardner and J. Luke for DNA sequencing, J. Anderson for generation of transgenic plants, and G. Pearson and J. Alvine for care of plants. The research was supported by NSF Cooperative Agreement BIR-8920216 to CEPRAP and by CEPRAP corporate associate, Sandoz Seeds.

\section{LITERATURE CITED}

Aoyama, T., and Chua, N. H. 1997. A glucocorticoid-mediated transcriptional induction system in transgenic plants. Plant J. 11:605-612.

Baker, B., Zambryski, P., Staskawicz, B., and Dinesh-Kumar, S. P. 1997. Signaling in plant-microbe interactions. Science 276:726-733.

Baulcombe, D. C. 1999. Fast forward genetics based on virus-induced gene silencing. Curr. Opin. Plant Biol. 2:109-113.

Baulcombe, D. C., Chapman, S., and Cruz, S. S. 1995. Jellyfish green fluorescent protein as a reporter for virus-infections. Plant J. 7:10451053.

Cao, Z., Henzel, W. J., and Gao, X. 1996. IRAK: A kinase associated with the interleukin-1 receptor. Science 271:1128-1131.

Chang, J. H. 1999. Molecular characterization of the interactions between tomato and Pseudomonas syringae pv. tomato. Ph.D. thesis. University of California, Davis.

Chang, J. H., Rathjen, J. P., Bernal, A. J., Staskawicz, B. J., and Michelmore, R. W. 2000. avrPto enhances growth and necrosis caused by Pseudomonas syringae pv. tomato in tomato lines lacking either Pto or Prf. Mol. Plant-Microbe Interact. 13:568-571.

Dangl, J. L., Dietrich, R. A., and Richberg, M. H. 1996. Death don't have no mercy-cell death programs in plant-microbe interactions. Plant Cell 8:1793-1807.

Douville, E. M., Afar, D. E., Howell, B. W., Letwin, K., Tannock, L., Ben-David, Y., Pawson, T., and Bell, J. C. 1992. Multiple cDNAs encoding the esk kinase predict transmembrane and intracellular enzyme isoforms. Mol. Cell. Biol. 12:2681-2689.

Flor, H. H. 1956. The complementary genetic systems in flax and flax rust. Adv. Genet. 8:29-54.

Frederick, R. D., Thilmony, R. L., Sessa, G., and Martin, G. B. 1998. Recognition specificity for the bacterial avirulence protein AvrPto is determined by Thr-204 in the activation loop of the tomato Pto kinase. Mol. Cell. 2:241-245.

Glazebrook, J. 1999. Genes controlling expression of defense responses in Arabidopsis. Curr. Opin. Plant Biol. 2:280-286.

Goodman, R. N., and Novacky, A. J. 1994. The Hypersensitive Reaction in Plants to Pathogens: A Resistance Phenomenon. American Phytopathological Society, St. Paul, MN, U.S.A.

Goring, D. R., and Rothstein, S. J. 1992. The S-locus receptor kinase gene in a self-incompatible Brassica napus line encodes a functional serine/threonine kinase. Plant Cell. 4:1273-1281.

Hanks, S. K., and Hunter, T. 1995. Protein kinases 6. The eukaryotic protein kinase superfamily: Kinase (catalytic) domain structure and classification. Faseb J. 9:576-596.

Hemmer, W., McGlones, M., Tsigelny, I., and Taylor, S. S. 1997. Role of the glycine triad in the ATP-binding site of cAMP-dependent protein kinase. J. Biol. Chem. 272:16946-16954.

Horsch, R. B., Fry, J. E., Hoffmann, N. L., Eichholtz, D., Rogers, S. G., and Fraley, R. T. 1985. A simple and general method for transferring genes into plants. Science. 227:1229-1231.

Jia, Y. L., Loh, Y. T., Zhou, J. M., and Martin, G. B. 1997. Alleles of Pto and Fen occur in bacterial speck-susceptible and fenthion-insensitive tomato cultivars and encode active protein kinases. Plant Cell. 9:6173.

Johnson, L. N., Noble, M. E., and Owen, D. J. 1996. Active and inactive protein kinases: Structural basis for regulation. Cell. 85:149-158.

Jones, J. D., Shlumukov, L., Carland, F., English, J., Scofield, S. R., Bishop, G. J., and Harrison, K. 1992. Effective vectors for transformation, expression of heterologous genes, and assaying transposon excision in transgenic plants. Transgenic Res. 1:285-297.

Jones, D. A., Thomas, C. M., Hammond-Kosack, K. E., Balint-Kurti, P. J., and Jones, J. D. 1994. Isolation of the tomato $C f-9$ gene for resistance to Cladosporium fulvum by transposon tagging. Science. 266:789-793.

Kopp, E. B., and Medzhitov, R. 1999. The Toll-receptor family and control of innate immunity. Curr. Opin. Immunol. 11:13-18.

Loh, Y. T., and Martin, G. B. 1995. The disease-resistance gene Pto and the fenthion-sensitivity gene Fen encode closely related functional protein kinases. Proc. Nat. Acad. Sci. U.S.A. 92:4181-4184.

Martin, G. B., Brommonschenkel, S. H., Chunwongse, J., Frary, A., Ganal, M. W., Spivey, R., Wu, T., Earle, E. D., and Tanksley, S. D. 
1993. Map-based cloning of a protein kinase gene conferring disease resistance in tomato. Science. 262:1432-1436.

Michelmore, R. W., and Meyers, B. C. 1998. Clusters of resistance genes in plants evolve by divergent selection and a birth-and-death process. Genome Res. 8:1113-1130.

Muzio, M., Ni, J., Feng, P., and Dixit, V. M. 1997. IRAK (Pelle) family member IRAK-2 and MyD88 as proximal mediators of IL-1 signaling. Science 278:1612-1615.

Parniske, M., Hammond Kosack, K. E., Golstein, C., Thomas, C. M. Jones, D. A., Harrison, K., Wulff, B. B. H., and Jones, J. D. G. 1997. Novel disease resistance specificities result from sequence exchange between tandemly repeated genes at the $C f-4 / 9$ locus of tomato. Cell 91:821-832.

Price, C. A., Reardon, E. M., and Lonsdale, D. M. 1996. A guide to naming sequenced plant genes. Plant Mol. Biol. 30:225-227.

Qureshi, S. T., Gros, P., and Malo, D. 1999. Host resistance to infection: Genetic control of lipopolysaccharide responsiveness by TOLL-like receptor genes. Trends Genet. 15:291-294.

Rathjen, J. P., Chang, J. H., Staskawicz, B. J., and Michelmore, R. W. 1999. Constitutively active Pto induces a Prf-dependent hypersensitive response in the absence of avrPto. EMBO (Eur. Mol. Biol. Organ.) J. 18:3232-3240.

Riely, B. K., and Martin, G. B. 2001. Ancient origin of pathogen recognition specificity conferred by the tomato disease resistance gene Pto. Proc. Natl. Acad. Sci. U.S.A. 98:2059-2064.

Rommens, C. M. T., Salmeron, J. M., Baulcombe, D. C., and Staskawicz, B. J. 1995a. Use of a gene expression system based on Potato virus X to rapidly identify and characterize a tomato Pto homolog that controls fenthion sensitivity. Plant Cell 7:249-257.

Rommens, C. M. T., Salmeron, J. M., Oldroyd, G. E. D., and Staskawicz, B. J. 1995b. Intergeneric transfer and functional expression of the tomato disease resistance gene Pto. Plant Cell 7:1537-1544.

Salmeron, J. M., Barker, S. J., Carland, F. M., Mehta, A. Y., and Staskawicz, B. J. 1994. Tomato mutants altered in bacterial disease resistance provide evidence for a new locus controlling pathogen recognition. Plant Cell 6:511-520.

Scofield, S. R., Tobias, C. M., Rathjen, J. P., Chang, J. H., Lavelle, D. T.,
Michelmore, R. W., and Staskawicz, B. J. 1996. Molecular basis of gene-for-gene specificity in bacterial speck disease of tomato. Science 274:2063-2065.

Sessa, G., D’Ascenzo, M., and Martin, G. B. 2000. Thr38 and Ser198 are Pto autophosphorylation sites required for the AvrPto-Pto-mediated hypersensitive response. EMBO (Eur. Mol. Biol. Organ.) J. 19:3157.

Song, W. Y., Wang, G. L., Chen, L. L., Kim, H. S., Pi, L. Y., Holsten, T., Gardner, J., Wang, B., Zhai, W. X., Zhu, L. H. and Ronald, P. C. 1995. A receptor kinase-like protein encoded by the rice disease resistance gene, Xa21. Science 270:1804-1806.

Song, W. Y., Pi, L. Y., Wang, G. L., Gardner, J., Holsten, T., and Ronald, P. C. 1997. Evolution of the rice Xa21 disease resistance gene family. Plant Cell 9:1279-1287.

Tang, X. Y., Frederick, R. D., Zhou, J. M., Halterman, D. A., Jia, Y. L., and Martin, G. B. 1996. Initiation of plant disease resistance by physical interaction of AvrPto and Pto kinase. Science 274:2060-2063.

Thompson, J. D., Gibson, T. J., Pewniak, F., Jeanmougin, F., and Higgins, D. G. 1997. The CLUSTAL X windows interface: Flexible strategies for multiple sequence alignment aided by quality analysis tools. Nucl. Acids Res. 25:4876-4882.

Tobias, C. M., Oldroyd, G. E. D., Chang J. H., and Staskawicz, B. 1999. Plants expressing the Pto disease resistance gene confer resistance to recombinant PVX containing the avirulence gene AvrPto. Plant J. 17: 41-51.

Van der Hoorn, R. A. L., Kruijt, M., Roth, R., Brandwagt, B. F., Joosten, M. H. A. J., and De Wit, P. J. G. M. 2001. Intragenic recombination generated two distinct $C f$ genes that mediate AVR9 recognition in the natural population of Lycopersicon pimpinellifolium. Proc. Natl. Acad. Sci. U.S.A. 98:10439-10498.

Wang, G. L., Ruan, D. L., Song, W. Y., Sideris, S., Chen, L., Pi, L. Y., Zhang, S., Zhang, Z., Fauquet, C., Gaut, B. S., Whalen, M. C., and Ronald, P. C. 1998. Xa21D encodes a receptor-like molecule with a leucine-rich repeat domain that determines race-specific recognition and is subject to adaptive evolution. Plant Cell 10:765-779.

Wesche, H., Gao, X., Li, X., Kirschning, C. J., Stark, G. R., and Cao, Z. 1999. IRAK-M is a novel member of the Pelle/Interleukin-1 receptorassociated kinase (IRAK) family. J. Biol. Chem. 274:19403-19410. 